\title{
Development of the Squalene-Synthesizing System during Early Stages of Pea Seed Germination
}

\author{
By T. R. Green and D. J. Batsted \\ Department of Biochemistry and Biophysics, Oregon State University, Corvallis, Oreg. 97331, U.S.A.
}

(Received 4 October 1971)

Pisum sativum has been the object of study by a number of investigators for the synthesis of isoprenoids. The capacity of germinating pea seeds to synthesize squalene, $\beta$-amyrin and sitosterol from $\left[2-{ }^{14} \mathrm{C}\right]$ mevalonate has been reported (Baisted, Capstack \& Nes, 1962). Changes in the capacity of germinating seeds to metabolize mevalonate at 1-day intervals during the first 5 days were also studied (Nes, Baisted, Capstack, Newschwander \& Russell, 1967). Cell-free preparations of germinated seeds were observed to be active in the synthesis of squalene and, to a much smaller extent, $\beta$-amyrin from mevalonate (Capstack, Rosin, Blondin \& Nes, 1965). The requirements necessary to optimize the synthesis of specific isoprenoids in homogenates of 10-day-old pea shoots and in young pea fruits have been investigated (Graebe, 1967, 1968). Most recently, a comparative study of germinating and developing seeds with respect to their capacity to synthesize sterols and triterpenes from mevalonate has been made (Baisted, 1971). The present communication reports the results of an investigation directed towards elucidation of the regulatory features of the isoprenoid pathway in relation to developmental changes initiated by the imbibition of water in pea seeds.

Materials. Pea ( $P$. sativum) seeds were of the Blue Bantam variety and were obtained from the Burpee Seed Co. (Riverside, Calif., U.S.A.). ATP and NADPH were purchased from Sigma Chemical Co. (St Louis, Mo., U.S.A.) as Sigma Grade Products. Glucose 6-phosphate dehydrogenase and alkaline phosphatase were purchased from P-L Biochemicals (Milwaukee, Wis., U.S.A.). 3-RS-[2.14C]Mevalonate was obtained as the dibenzylethylenediamine salt from New England Nuclear Corp. (Boston, Mass., U.S.A.). It was converted into the sodium salt before use, when it had specific radioactivity $5.9 \mu \mathrm{Ci} / \mu \mathrm{mol}$. G.l.c. supplies were obtained from Perco Supplies (San Gabriel, Calif., U.S.A.).

Methods. Sets of 100 seeds, the seed coats of which were partly broken so as to enhance a uniform uptake of water, were germinated in distilled water in the dark at $24^{\circ} \mathrm{C}$. At the end of a specific time-interval the seeds were thoroughly washed with water and a crude homogenate was prepared essentially according to the procedure of
Capstack et al. (1965). The seeds were homogenized in a $100 \mathrm{~mm}$-sodium-potassium phosphate buffer, pH 7.4, containing $10 \mathrm{~mm}$-magnesium sulphate and $10 \mathrm{~mm}-\mathrm{GSH}$. When sucrose was present it was $0.45 \mathrm{M}$ in the buffer. The crude homogenate, after filtration through cheesecloth, was centrifuged at $40000 \mathrm{~g}$ for $10 \mathrm{~min}$. The supernatant was used in the assays.

Assay of squalene-synthesizing activity was made with reaction mixtures containing $3 \mathrm{ml}$ of the supernatant to which were added $181 \mathrm{nmol}$ each of ATP and NADPH, 2 units of glucose 6-phosphate dehydrogenase, $10 \mu \mathrm{mol}$ of glucose 6-phosphate and $2 \mu \mathrm{Ci}$ of $R S-\left[2-{ }^{14} \mathrm{C}\right]$ mevalonate $(0.34 \mu \mathrm{mol})$ to give a total volume of $3.2 \mathrm{ml}$. The incubation was conducted at $24^{\circ} \mathrm{C}$ for $1 \mathrm{~h}$ and was terminated with $2 \mathrm{ml}$ of $20 \%(\mathrm{w} / \mathrm{v})$ potassium hydroxide. The solution was heated on a steam bath for $2 \mathrm{~h}$ and the nonsaponifiable lipid was extracted with several volumes of ether. Radioactivity in this extract was found to be associated only with squalene.

Analysis of the non-saponifiable lipid fraction isolated from incubation mixtures representing several different germination stages was made by t.l.c. on silica gel $\mathrm{G}$ in ethyl acetate-heptane $(3: 22$, $v / v)$ and on silver nitrate-silica gel $G(3: 97, w / w)$ in benzene.

Phosphorylated intermediates were identified by a combination of several ion-exchange and paperchromatographic systems as described previously (Green \& Baisted, 1970). Prenyl pyrophosphates were also identified by chemical and enzymic procedures according to the method of Popják (1969). For routine measurements the aqueous phase was made acidic ( $\mathrm{pH}$ l) with dilute hydrochloric acid, after removal of squalene, and the prenols generated from the allylic pyrophosphates were extracted into ether at neutral pH. Alternatively, the $\mathrm{pH}$ of the aqueous phase, after removal of squalene, was adjusted to 9.5 and hydrolysis of the prenyl pyrophosphates was effected with alkaline phosphatase. Free prenols were extracted as before. Samples of the ether-extracted prenols were submitted to g.l.c. on a $6 \mathrm{ft} \times \frac{1}{4}$ in acid-washed dimethylchlorosilanetreated Chromosorb W support coated with $20 \%$ butanediol succinate polyester. The column was run at $80^{\circ} \mathrm{C}$ for $6 \mathrm{~min}$ and then programmed at 


$$
\begin{gathered}
\text { Mevalonate } \rightarrow \text { 5-Phosphomevalonate } \rightarrow \text { 5-Pyrophosphomevalonate } \\
\begin{array}{c}
\downarrow \\
\text { Geranyl pyrophosphate } \\
\downarrow
\end{array} \\
\text { Farnesyl pyrophosphate }
\end{gathered} \rightarrow\left\{\begin{array}{c}
\text { Isopentenyl pyrophosphate } \\
1 \downarrow \\
\text { 3,3-Dimethylallyl pyrophosphate }
\end{array}\right.
$$

Scheme 1. Pathway for the conversion of mevalonate into squalene.

$20^{\circ} \mathrm{C} / \mathrm{min}$ to $180^{\circ} \mathrm{C}$ with an argon flow rate of $40-50 \mathrm{ml} / \mathrm{min}$.

Radioactivity measurements of organic extracts were made by liquid-scintillation counting on a Packard Tri-Carb model 574 counter with a fluor mixture of 2,5-diphenyloxazole (PPO) $(0.4 \%)$ and 1,4 - bis - (5 - phenyloxazol - 2 - yl)benzene (POPOP) $(0.003 \%)$ in toluene. Radioactivity in prenols separated by g.l.c. was measured with a NuclearChicago model 4998 ionization detector. The detector was attached to a Beckman GC4 gas chromatograph equipped with a flame ionization detector and a splitter that permitted nine-tenths of the effluent from the column to flow through the counter. Distribution of label on paper and thinlayer chromatograms was determined by scanning on a Packard model 7301 strip scanner.

Results and discussion. The pathway by which mevalonate is converted into squalene is shown in Soheme 1.

The incorporation of mevalonate into squalene by incubation mixtures was linear with time after an initial lag period of several minutes. Linearity of the incorporation was maintained for at least $60 \mathrm{~min}$ beyond the lag period. The rate of incorporation of label into squalene represents the activity of the rate-limiting enzyme in squalene synthesis, and the initial lag period presumably represents the time required for substrate to saturate this rate-limiting enzyme. The essays were reproducible to within $\pm 5 \%$, as demonstrated by assaying the homogenates from five sets of seeds germinated for the same period of time.

Fig. 1 shows the incorporation of ${ }^{14} \mathrm{C}$ into squalene and prenols for each germination stage of seeds homogenized in the presence and in the absence of sucrose. In the presence of sucrose it is clear that dramatic increases in squalene-synthesizing capacity occur as development progresses. Two distinct phases of increasing activity (I and II) are evident. These are followed by a phase in which a steady decline in activity occurs (III). This loss of activity appears to be the result of the appearance of an inhibitor, as evidenced by an examination of the intrinsic stability of the extracts of phases II and III separately and in 1:1 mixture. Paper-chromatographio, t.l.c. and g.l.c. analysis of incubation

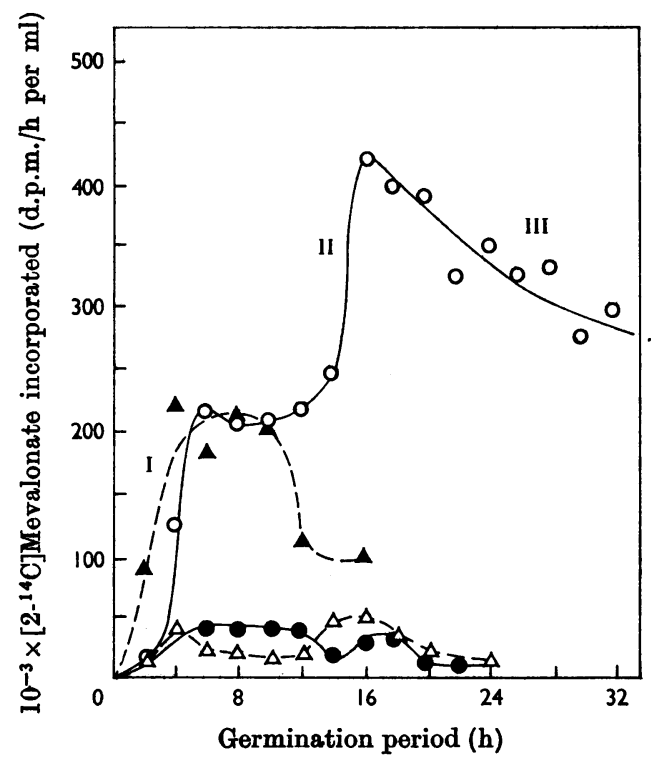

Fig. 1. Development of the squalene-synthesizing system during pea seed germination. Homogenates were prepared in the presence and in the absence of sucrose. Both squalene and acid-labile prenyl pyrophosphates were assayed. The changes in activity expressed per $\mathrm{mg}$ of protein were essentially the same as those shown in the figure. Sucrose present: $O$, squalene; $\bullet$, acid-labile prenyl pyrophosphates. Sucrose absent: $\Delta$, squalene; $\Delta$, acid-labile prenyl pyrophosphates.

mixtures (with homogenates prepared in the pres. ence of sucrose) after steady-state conditions had been achieved (after the lag period) showed label to be present in mevalonate, 5-phosphomevalonate, 5-pyrophosphomevalonate, pyrophosphate, 3,3isopentenyl/dimethylallyl pryophosphate and squalene; no label accumulated in geranyl pyrophosphate, farnesyl pyrophosphate or higher allylic pyrophosphates. This was shown to be the case in phase 1, II and III, and suggested pyrophosphate/ isopentenyl/3,3-dimethylallyl pyrophosphate prenyltransferase to be the rate-limiting enzyme in squalene synthesis for all three phases. Direct assays of each of the enzymes from mevalonate 
kinase to squalene synthetase during these same stages of germination have confirmed these observations (Green \& Baisted, 1971).

In preliminary studies sucrose was omitted from the homogenizing medium. These conditions result in a nearly complete loss of capacity for squalene synthesis (Fig. 1). However, the formation of prenols during phase I under these conditions indicates prenyltransferase activity to be undiminished. Clearly, then, the isolation and/or stability of squalene synthetase is immensely improved when sucrose is present during homogenization.

Phase II reveals a second burst of prenyltransferase activity as germination progresses. This increase is observed only when sucrose is present during homogenization. When sucrose is omitted from the buffer medium, prenyltransferase activity decreases during this phase.

These findings are consistent with the presence of two distinct prenyltransferases, which differ in their properties with respect to their isolation and/or stability in a sucrose-containing medium. It is likely that these activities are present in two different compartments of the cell. Such a suggestion supports the work of Goodwin and his coworkers (Goodwin, 1965; Treharne, Mercer \& Goodwin, 1966), who rationalized their results on the differential incorporation of ${ }^{14} \mathrm{CO}_{2}$ and $\left[2-{ }^{14} \mathrm{C}\right]$ mevalonate into terpenoids in a number of monocotyledons and dicotyledons on the basis that certain of the enzymes are located both inside and outside the chloroplast. The two phases of squalene synthesis that we observe may result from the sequential appearance of distinct prenyltransferase activities associated with the cytoplasm and developing chloroplasts during pea seed germination.

This work was supported by U.S. Public Health Service Grant AM09265 from the National Institutes of Health. T. R. G. was supported by a National Defence Education Act Fellowship. This work represents part of the Ph.D. Thesis of T. R. G. at Oregon State University. Request for reprints should be addressed to D. J. B.

Baisted, D. J. (1971). Biochem. J. 124, 375.

Baisted, D. J., Capstack, E., jun. \& Nes, W. R. (1962). Biochemistry, Easton, 1, 537.

Capstack, E., jun., Rosin, N., Blondin, G. A. \& Nes, W. R. (1965). J. biol. Chem. 240, 3258.

Goodwin, T. W. (1965). In Biosynthetic Pathways in Higher Plants, p. 57. Ed. by Pridham, J. E. \& Swain, T. New York: Academic Press Inc.

Graebe, J. E. (1967). Science, N.Y., 157, 73.

Graebe, J. E. (1968). Phytochemistry, 7, 2003.

Green, T. R. \& Baisted, D. J. (1970). Analyt. Biochem. 38, 130.

Green, T. R. \& Baisted, D. J. (1971). Fedn Proc. Fedn Am. Socs exp. Biol. 30, 1480 (Abstr.).

Nes, W. R., Baisted, D. J., Capstack, E., jun., Newschwander, W. W. \& Russell, P. T. (1967). In Biochemistry of Chloroplasts, vol. 2, p. 273. Ed. by Goodwin, T. W. New York: Academic Press Inc.

Popják, G. (1969). In Methods in Enzymology, vol. 15, p. 393. Ed. by Clayton, R. B. New York: Academic Press Inc.

Treharne, K. J., Mercer, E. I. \& Goodwin, T. W. (1966). Biochem. J. 99, 239. 